\title{
Renuncia al arbitraje previsto en un tratado: el caso ecuatoriano
}

\author{
Xavier Andrade Cadena*
}

\section{SUMARIO}

1. Introducción 2. La renuncia en teoría. Convergencia de intereses personales, estatales e internacionales 2.1. La persona como sujeto de derecho internacional 2.1.1. Teoría de los derechos directos 2.1.2. Teoría de los derechos derivados 2.1.3. Las teorías aplicadas al objeto de esta investigación 2.2. Los límites de la autonomía de la voluntad en el derecho y orden público internacionales 2.2.1. Propuesta de test 3. La renuncia en la práctica. Una posición en evolución 3.1. Jurisdicción alternativa o exclusiva 3.2 preeminencia de la autonomía de la voluntad 4. Conclusiones

\section{INTRODUCCIÓN}

En los últimos años, el Estado ecuatoriano ha adoptado medidas destinadas a alejarse de la práctica del arbitraje, particularmente del originado en tratados bilaterales de inversión. La intención del gobierno de turno ha sido particularmente tratar de blindar al país ante las demandas de inversionistas extranjeros'.

- Abogado y Doctor en Jurisprudencia, Pontificia Universidad Católica del Ecuador (PUCE). Master en Derecho, McGill University. Profesor de Arbitraje Internacional, PUCE y Universidad San Francisco de Quito. Socio, Andrade Veloz \& Asociados, Ecuador.

1. La posición del gobiemo ecuatoriano ha sido ampliamente cubierta por la prensa local. Consúltense, por ejemplo, los diarios El Comercio y El Universo. 
Con esta finalidad en mente, el gobierno ecuatoriano, en diciembre de 2007, notificó al CIADI que de conformidad con el artículo 25(4) del Convenio del CIADI no "consentirá en someter a [su] jurisdicción las diferencias que surjan en materias relativas al tratamiento de una inversión, que se deriven de actividades económicas relativas al aprovechamiento de recursos naturales como petróleo, gas, minerales u otros" 2 . Adicionalmente indicó que:

"Todo instrumento contentivo de la voluntad previamente expresada por la República del Ecuador en someter esta clase de diferencias a la jurisdicción del Centro, que no se haya perfeccionado mediante el expreso y explícito consentimiento de la otra parte previa la fecha de presentación de esta notificación, es retirado por la República del Ecuador, con eficacia inmediata a partir de esta fecha" 3 .

Posteriormente, en octubre de 2008, Ecuador promulgó su nueva Constitución ${ }^{4}$ en la que, al tiempo de ratificar la validez de sistema arbitral', se limitó la posibilidad de que el Estado pueda pactar nuevos tratados internacionales en los que se prevea que las disputas contractuales o comerciales entre el Estado y personas privadas se sometan a instancias de arbitraje internacional, salvo que dichas instancias sean "regionales" 6 .

2. Notificación de Ecuador al CIADI del 4 de diciembre de 2007, http://icsid.worldbank org/ICSID/ICSID/ViewNewsReleases jsp.

3. Ihid. Sobre los efectos de csta notificación, véase a Montañes, Marco Tulio y Andrade cadena, Xavier. "Introductory Note to Ecuador's Notice under ICSID Article 25(4)". En: International Le'gal Materials, Volumen 47. Washington D.C: American Society of Intemational Law, 2008, pp. 154-161.

4. Sobre el arbitraje en la nueva Constitución, véase a ANDRADE CADENA, Xavier. "Breves reflexiones sobre el arbitraje en la nueva Constitución ecuatoriana". En: Revista de Arbitragem e Mediaça. São Paulo: Ed. Revista Dos Tribunais, 2009, pp. 351-366.

5. Articulo $190 \mathrm{de}$ la Constitución: "Se reconoce el arbitraje, la mediación y otros procedimientos alternativos para la solución de conflictos. Estos procedimientos se aplicarán con sujeción a la ley, en materias en las que por su naturaleza se pueda transigir".

6. Articulo 422 de la Constitución "No se podra celebrar tratados o instrumentos internacionales en los que el Estado ecuatoriano ceda jurisdicción sobcrana a instancias de arbitraje intemacional, en controversias contractuales o de indole comercial, entre el Estado y personas naturales o juridicas privadas.

Se exceptủan los tratados c instrumentos intemacionales que establezcan la solución de controversias entre Estados y ciudadanos en Latinoamérica por instancias arbitrales regionales o por órganos jurisdiccionales de designación de los paises signatarios. No podrán intervenir jueces de los Estados que como tales o sus nacionales sean parte de la controversia", 
El descontento del gobierno frente al sistema CIADI ${ }^{7}$ llevó a que, en julio de 2009, Ecuador denuncie el Convenio del CIADI, convirtiéndose después de Bolivia en el segundo país en separarse del tratado.

Adicionalmente, dado que la mayoría de arbitrajes que enfrenta el Ecuador se originan en tratados bilaterales de inversión (TBIs) suscritos con países exportadores de capital, el gobierno solicitó a la Asamblea Nacional su autorización para poder terminarlos anticipadamente ${ }^{8}$.

Por último, en vista de que las medidas anotadas no tienen el efecto inmediato de blindaje perseguido, el gobierno, en ocasiones, ha optado por un camino más efectivo: acordar con el inversionista que las disputas sean resueltas en un foro distinto al previsto en un tratado, renunciando a someterlas a tal instancia.

A manera de ejemplo -y también como elemento de análisis de este trabajo-, transcribimos una estipulación de un contrato suscrito entre el Ecuador y un inversionista español en la que las partes, luego de seleccionar un foro arbitral local para resolver disputas, dejaron en claro que:

"El arbitraje realizado de conformidad con esta Cláusula será el único y exclusivo foro competente para la resolución de las controversins. Por lo tanto, las Partes renuncian a la jurisdicción ordinaria y no podrán alegar en su defensa incompetencia del Tribunal de Arbitraje ni inmunidad soberana, ni sujeción a jurisdicciones distintas previstas en acuerdos de protección recíprocas de inversiones $u$ otros instrumentos celebrados por la República del Ecuador o cualquier otra excepción semejante que cuestione la competencia exclusiva y excluyente del Tribunal de Arbitraje, en cualquier procedimiento de solución de

7. Véanse notas de prensa al respecto. Por ejemplo:

http://www.elcomercio.com/solo_texto_search asp?id noticia=190521\&anio $=2009 \& \mathrm{mes}=8 \&$ dia $=3$. http://www.clcomercio.com/solo texto search asp?id noticia $185948 \& a n i 0=2009 \& m e s=7 \& d i a=3$.

8. A la presente fecha, la Cortc Constitucional ha declarado inconstitucionales algunas disposíciones de varios TBIs, lo cual permitiria a la Asamblea Nacional autorizar la denuncia de los tratados. 
las controversias, con las excepciones previstas en este Contrato.[...] Las Partes renuncian a los mecanismos de solución de controversias constantes en los convenios suscritos por el Gobierno de la República del Ecuador relacionados con la Promoción y Protección Recíproca de lnversiones, respecto de cualquier tema relacionado, originado o vinculado con la ejecución, terminación o efectos del presente Contrato"."

Más recientemente, en el contexto de la renegociación de contratos que el gobierno lleva a cabo con varias empresas petroleras, el régimen propuso un proyecto de Contrato de Prestación de Servicios cuya cláusula de solución de disputas, a más de prever instancias de conciliación y arbitraje administradas por la Corte Permanente de Arbitraje, señala:

"Elección y renuncia.- El arbitraje previsto en la presente cláusula valdrá como elección de la vía para la resolución de las desavenencias derivadas del presente Contrato o que guarden relación con el mismo de conformidad con lo previsto en cualquier Tratado sobre Promoción y Protección de Inversiones que pudiera ser invocado por la Contratista.

Las Partes renuncian expresamente a resolver las desavenencias derivadas del presente Contrato o que guarden relación con el mismo mediante arbitraje de conformidad con el Mecanismo creado por el Convenio sobre Arreglo de Diferencias Relativas a Inversiones entre Estados y Nacionales de otros Estados (CIADI)".10

Renuncias como las indicadas son novedosas en el derecho internacional, sobre todo porque la capacidad de un inversionista de renunciar a un derecho plasmado en un tratado internacional, que no ha sido acordado por él sino por su Estado, podría ser cuestionable.

9. Énfasis del autor. Contrato de Concesión de servicios de telccomunicaciones suscrito entre la Secretaria Nacional de Telecomunicaciones del Ecuador y la compañia Otecel S.A., filial de la española Telefónica, el 20 de noviembre de 2008, Cláusulas 68(6)(c) y 72(3).

10. Este proyecto de contrato ha circulado ampliamente dentro de la comunidad jurídica de negocios ecuatoriana. A la fecla de este trabajo, no se conoce su versión final. 
Este trabajo trata de tomar una posición ante dicha interrogante, para lo cual, en una primera y teórica parte, se analiza la doctrina y jurisprudencia relativa a los derechos previstos en un tratado y la facultad que tendrían los particulares de renunciarlos (Sección 2). La segunda parte mira la hipótesis desde la práctica, específicamente, para dilucidar cómo los tribunales arbitrales aplican (o se espera que apliquen) la teoría estudiada (Sección 3).

\section{LA RENUNCIA EN TEORÍA. CONVERGENCIA DE INTERESES PERSONALES, ESTATALES E INTERNACIONALES}

\subsection{La Persona como Sujeto de Derecho Internacional}

No cabe duda de que la teoría clásica del derecho internacional, según la cual únicamente los Estados eran sujetos de derecho internacional, ha evolucionado. En la actualidad, las personas, lejos de ser consideradas objetos, son reconocidos sujetos con capacidad de goce y ejercicio de derechos y obligaciones emanados del derecho internacional.

Esta realidad es más evidente en unas áreas que en otras. Por ejemplo, en el ámbito de los derechos humanos, la posibilidad de que una persona ejerza derechos individuales previstos en instrumentos internacionales, es innegable. Así, por ejemplo, la Declaración Universal de los Derechos Humanos de 1948 y la Convención Americana sobre Derechos Humanos de 1969 son frecuentemente enunciadas por particulares para reclamar violaciones a derechos humanos.

En el área del arbitraje de inversión sucede algo parecido. Se observa recurrentemente que los inversionistas exigen a los Estados receptores de sus inversiones el cumplimiento de las garantías previstas en un tratado. 
Cabe preguntarse, entonces, dentro del contexto de las renuncias objeto de esta investigación, si los particulares inversionistas son titulares de los derechos cuyo cumplimiento reclaman al Estado receptor. La respuesta no es evidente, pues estos derechos no ha sido pactados por ellos sino por los Estados de los cuales son nacionales.

La cuestión puede analizarse, al menos, desde la perspectiva de dos escuelas de pensamiento: la teoría de los derechos directos y la teoría de los derechos derivados'1.

\subsubsection{Teoria de los derechos directos}

Esta teoría es, de cierta manera, inusual dentro del derecho internacional clásico porque propone que algunos tratados otorgan derechos a particulares y no sólo a entes públicos. La Corte Internacional de Justicia acogió esta doctrina en el caso LaGrand en el que, a propósito de la Convención de Viena sobre Relaciones Consulares de 1963, sostuvo:

"[...] Habida cuenta del tenor de estas disposiciones, la Corte conchuye que el párrafo 1 del artículo 36 crea derechos individuales que, en virtud del articulo primero del protocolo de suscripción facultativa, pueden ser invocados ante la Corte por el Estado de la nacionalidad del detenido. En este caso, estos derechos han sido violados"'?2.

Concomitantemente, los tratados internacionales también pueden crear obligaciones para los particulares. Por ejemplo, es

11. Sobre estas escuelas véase, por ejemplo, a Douclas, Zachary. "The Hybrid Foundations of Investment Treaty Arbitration". En: British Fearheok of International Law'. No. 74. Oxford: Oxford University Press, 2003, pp. 151-290; MClacillan, Campbell. Shołe, Laurence y Weaniger. Matthew. Litcrnational luvestment Arbitration: Suhstantive Principles. Oxford: Oxford University Press. 2007, pp. 60-65.

12. Énfasis del autor. LaGrand, Alemania vs. Estados Unidos de América, arrêt, C.1.J. Recucil 2001, p. 466, par. 77. Traducción del autor de su versión original: "[... ] Compte temu du lihellé de ces dispostitoms, la Cour conclat que le paragraphe I de l'article 36 crie des drrits individinels qui, en vertu de l'article premice du protocole de signature faculative, peavent être inoques devant la Cour par I'Etat doun la personne détente a la nationalicé. En l'espéce, ces dorits ont été violés". 
claro que la Convención para la Prevención y Castigo del Delito de Genocidio o la Convención de las Naciones Unidas sobre el Derecho del Mar imponen obligaciones a las personas..

\subsubsection{Teoria de los derechos derivados}

Esta teoría se forma a partir de la figura de la protección diplomática, según la cual un Estado es responsable de los daños que sus acciones $u$ omisiones causen a los nacionales de otro Estado. El Estado del nacional afectado puede, en aplicación de esta institución, reclamar una reparación al Estado infractor como si se tratase de sus propios derechos. La anterior Corte Permanente de Justicia Internacional en el caso Movrommatis sostuvo lo siguiente:

"[...] Al asumir el caso de uno de sus nacionales y acudir a la acción diplomática o a procedimientos judiciales internacionales en su nombre, el Estado en realidad se encuentra haciendo valer sus propios derechos -sus derechos de asegurar, en la persona de sus nacionales, el respeto a las normas del derecho internacional"13.

Esta teoría se encuentra cada vez más en desusoli, particularmente porque los particulares no pueden obligar a sus Estados a protegerlos. La intervención estatal es siempre discrecional, como observó la Corte Internacional de Justicia en el caso Barcelona Traction:

13. The Mostrmmatis Palestine Concessints, Grecia vs. Reino Unido, Collection of Judgments, Scric A, No. 2, p. 12. Traducción del autor de su version original: "[...] By taking up the case of one of its subjects and by resorting to diplomatic action ar international judicial procecdings on his behalf, a State in reality is asserting its own rights - its rights to ensure. in the person of its subjects, respect for the rules of international law".

14. Entre estas razones, podemos scñalar: (a) el inversor debe agotar previamente los recursos disponibles en el pais anfitrión; (b) la decisión del Estado del inversor de presentar un reclamo a otro Estado es discrecional y sujeta a varias consideraciones, algunas ajenas a los intereses directos del particular; (c) un Estado puede dejar de cjereer la protección diplomática en cualquier momenk; y (d) los daños y perjuicios rechamados son aquellos evaluados por el Estado en virtud de un incurplimiento alegado y no por el particular. Sobre este tema, véase, por cjemplo, a Hofrstann, Anne. "The Investor's Right to Waive Access to Protection under A Bilateral Investment Treaty". En: ICSID Review - Foreign Imestment Law Journal, Vol. 22(1). Washington D.C., 2007, pp. 42-44. 
"[...] dentro de los límites fijados por el derecho internacional, un Estado puede ejercer su protección diplomática mediante los medios y medidas que éste considere apropiados, ya que está haciendo valer sus propios derechos. Si las personas naturales o jurídicas a nombre de quien el Estado actúa consideran que sus derechos no se encuentran suficientemente protegidos, ellas no tienen ningún recurso en el derecho internacional [...] El Estado debe ser considerado como el único juez para decidir si proveerá esta protección, en qué medida y hasta cuando lo hará. Él posee en ese respecto un poder discrecional cuyo ejercicio puede depender de consideraciones, especialmente políticas, extrañas al caso en cuestión"15.

En el dominio del arbitraje internacional, la teoría de los derechos derivados fue adoptada en el caso Lowen administrado bajo las reglas del TLCAN. El tribunal, luego de mencionar que el arbitraje comercial internacional (regulado primordialmente por el derecho internacional privado) y el arbitraje TLCAN (regulado por el derecho internacional público) "no tienen nada en común", acotó que "no existe justificación para transferir normas derivadas del derecho privado al campo del derecho internacional, bajo las cuales los demandantes, por conveniencin, podrín ejercer derechos que pertenecen originalmente a los Estados contratantes" 16 .

15. Barcetona Traction, Light and Power Company: Limited, Bélgica vs. Esparia, arrèt, C.I.J. Recueil 1970, p. 3, par. 78-79. Traducción del autor de su versión original: "La Cour rappelle que, dans les limites fixces par le droit international, un Efat peat exercer sa protection diplomatique par les moyens et dans la mesure qu' il juge appropricis, car c'est son droit propre qu'il fait valoir. Si les personnes physiques ou morales pour le compte de qui il agit estiment que leurs droits ne sont pas sifffisumment protègès, elles demeurent sans recours en droit international $[. .$.$] L'Etat doit étre consi-$ déré comune seul maitre de décider s'il accordera sa protection, dans quelle mesure il le fera et quand il y mettra fin. Il posséde à cet igurd un pouvoir discrétionnaine dont l'exencice peut dépendre de cunsidérations, d'ondre politique notamment, étrangères au cas d'espèce".

16. The Loewen Group. Inc. and Raymond L. Locwen vs. Estados Unidos de América, Caso CIADI No. ARB(AF)/98/3, Laudo del 26 de junio de 2003, par 233. Traducción del autor de su versión original: "There is no warrant for transferring rules derived from private law into a field of international law where clainants are permitted for convenience to enforce what ane in origin the rights of Party states". 


\subsubsection{Las teorias aplicadas al objeto de esta investigación}

La novedad de la materia, sumada a la cautela de los académicos, hicieron difícil, hasta hace poco, encontrar luces sobre la aplicabilidad de estas teorías a los derechos de los inversionistas previstos en tratados de inversión.

De hecho, el Proyecto de Artículos sobre Responsabilidad del Estado por Hechos Internacionalmente Ilícitos, adoptado por la Comisión de Derecho Internacional (CDI) de las Naciones Unidas en el año 2001, no acoge ninguna de las teorías. El artículo 33 del dicho Proyecto determina que

"[1] as obligaciones del Estado responsable [...] pueden existir con relación a otro Estado, a varios Estados o a la comunidad internacional en su conjunto [...] sin perjuicio de cualquier derecho que la responsabilidad internacional del Estado pueda generar directamente en beneficio de una persona o de una entidad distinta de un Estado"17.

JAMES CRAWFORD, rapporteur especial de la CDI, haciendo referencia a los tratados bilaterales de inversión, comenta que el Proyecto no refleja una posición sobre si los derechos emanados de tales tratados pertenecen a los inversionistas o a los Estados:

"[...] lo que denota claramente el Artículo 33 es que las obligaciones secundarias derivadas de un incumplimiento pueden deberse directamente al beneficiario de la obligación, en este caso el inversionista, quien, al iniciar un proceso arbitral de conformidad con el tratado, actúa efectivamente en la situación como un titular secundario de los derechos. Por lo tanto, una nueva relación legal -si no existía antes- se ha creado directamente entre el inversionista y el Estado responsable. En consecuencia, un tratado bilateral de inversión, a cierto nivel, desagrega los intereses legales agrupados bajo la fórmula Movrommatis"18.

17. Énfasis del autor.

18. CRAwFoRD, James. "The ILC's Articles on Responsability of States for Internationally Wrongfull Acts: A Retrospect". En: American Journal of International Law. 96 Am. J. Int'l L. 874. Wastington D.C.: American Society of International Law, 2002, p. 888. 
A pesar de lo anterior, y desde luego sin subestimar lo novedoso y complejo del tema, podemos adelantar que las cortes y tribunales arbitrales empiezan a inclinarse por la teoría de los derechos directos.

Por ejemplo, en el campo del arbitraje CIADI, el tribunal del caso Gas Natural vs. Argentina señaló que:

"El sistema del Convenio del CIADI y de los tratados bilaterales de inversión consiste en que, en las referidas circunstancias, el inversor extranjero adquiere derechos en el marco del Convenio y del tratado, incluyendo, en especial, la legitimación para promover un arbitraje internacional" 19 .

Lo anterior tiene sentido, pues parece claro que las normas del Convenio del CIADI crean un sistema que permite, tanto a los Estados contratantes como a sus nacionales, iniciar procedimientos arbitrales para resolver sus disputas de inversión ${ }^{20}$. BROCHES, conocido arquitecto del Convenio, lo explica de siguiente manera:

"Desde el punto de vista legal, la característica más sorprendente del Convenio es que establece firmemente la capacidad de un individuo o de una corporación de proceder directamente en contra de un Estado en un foro internacional, contribuyendo, de esta manera, al creciente reconocimiento de las personas como sujetos de derecho internacional"21.

19. Énfasis del autor. Gas Natural SDG, S.A. us. Repuiblica de Argentina, Caso CIADI No. ARB 03/10, Decisión sobre Jurisdicción, 17 de junio de 2005, par. 34.६

20. El articulo $36 \mathrm{del}$ Convenio del CIADI establece que "[c]ualquier Estado Contratante o nacional de un Estado Contratante [puede] incoar un procedimicnto de arbitraje [... $]^{\prime \prime}$.

21. Brocues, Aron. "The Convention The Convention on the Settlement of Investment Disputes between States and Nationals of Other States". En: Selected Essays: Norld Bank, ICSID, and Other Subjects of Public and Private International Law: La Haya: Kluwer, 1995, p. 198. Traducción del autor de su versión original: "Uflrom a legal point of view' the most striking feature of the Comention is that it firmly establishes the capacity of a private individital or a corporation to proceed directly' against a State in an international forum, thus contributing to the grmwing recognition of the indivi. dtal as a subject of international law". 
El sistema CIADI, de hecho, considera que el ejercicio de derechos derivados es incompatible con el Convenio. $\mathrm{Si}$ un inversionista ha demandado directamente al Estado receptor de su inversión, sin la intermediación de su propio Estado, éste está prohibido de brindarle protección diplomática. El artículo 27 del Convenio de CIADI señala:

"Ningún Estado Contratante concederá protección diplomática ni promoverá reclamación internacional respecto de cualquier diferencia que uno de sus nacionales y otro Estado Contratante hayan consentido en someter o hayan sometido a arbitraje conforme a este Convenio, salvo que este último Estado Contratante no haya acatado el laudo dictado en tal diferencia o haya dejado de cumplirlo"22.

Las cortes también han empezado a endosar la teoría de los derechos directos. Por ejemplo, la Corte de Apelación inglesa en el caso Occidental vs. Ecundor señaló:

"El hecho de que los tratados puedan bajo el derecho internacional moderno otorgar derechos directos a favor de particulares es algo bien establecido, particularmente cuando el tratado prevé un mecanismo de resolución de conflictos que puede ser operado por tales particulares que actúan a nombre propio y sin la intervención o siquiera el consentimiento de su Estado"23.

22. El Informe de los Directores Ejecutivos acerea del Convenio, en su párrafo 33, ahonda sobre esta prohibición: "Cuando un Estado receptor consiente en someter al Centro la diferencia con un inversionista, otorgando asi al inversionista acceso directo a una jurisdicción de caracter internacional, dicho inversionista no debe quedar en posición de pedir a su Esıado que respalde su caso ni se debe permitir a ésle que lo haga. En consecuencia, el Articulo 27 prohibe expresamente al Estado Contratante dar protección diplomática [...]".

Esta incompatibilidad fue corroborada por cl tribunal del caso Enron vs. Argentina, que consideró que "precisamente el mérito del Converio CIADI es que hà superado las deficiencias de la protección diplomática en el que el inversionista estaba sujeto a cualquicr determinación politica o legal que su Estado podria hacer respecto a su reclamo". Traducción del autor de su versión original: "This is pre. cisely the merit of the ICSID Convention in that it overcame the deficiencies of diplomatic protection where the investor was subject to whatever political or legal determination the State of nationality uvuld make in respect of its claim". Enron Corporation y Ponderosa Assets, L.P. vs. Argentina, Caso CIADI No. ARB/01/3, Decisiön sobre Jurisdieción, 14 de enero de 2004, par, 48.

23. Occidental Exploration and Production Company vs. Eczudor, Decisión del 9 de septiembre de 2005, [2005] EWCA Civ 1116, par. 19. Traducción del autor de su versión original: "That treaties may' in modern international law give rise to direct rights in faver of individuals is well established, particu- 
Esta Corte, citando a ZACHARY Douglas, además sostuvo que "la presunción fundamental en el régimen de los tratados de inversión es que claramente el inversionista presenta una acción basado en la defensa de sus propios derechos y no los de su Estado"24.

Así las cosas, parecería que adoptar la teoría de los derechos directos en el denominado derecho de inversión facilitaría notablemente la tarea de un inversionista que desee renunciar a su derecho a acudir a los foros arbitrales previstos en un tratado. Esto no ocurriría, por el contrario, bajo la teoría de los derechos derivados, pues es notorio que una persona no podría renunciar a algo que no posee.

Pese a lo dicho, el hecho de que una persona sea titular de derechos y obligaciones emanados del derecho internacional no significa necesariamente que ella pueda, por esta sola razón, renunciar a tales derechos y obligaciones, pues, como se comenta a continuación, el mismo derecho internacional o el orden público internacional podrían limitar tal facultad.

\subsection{Los Límites de la Autonomía de la Voluntad en el Derecho y Orden Público Internacionales}

La facultad de una persona de ejercer o dejar de ejercer (por ejemplo, mediante renuncia) un derecho proclamado por el derecho internacional, podría encontrar su límite natural en el mismo derecho internacional o en el orden público internacional. Consiguientemente, no podemos aseverar que una persona por ser titular de un derecho tenga la facultad automática de renunciar a ejercerlo ${ }^{25}$.

larly where the treaty provides a dispute nesolution mechanism capable of being operated by such individuals acting on their own behalf and without their national state's involveneut or even consent".

24. Ihid, par, 20. Traducción del autor de su version original: "The fundamental assumption underlving the insestment treaty regine is clearly that the imestor is hringing a canse of action based upon the vindication of its ann rights rather than those of its national State".

25. Para una clara exposición sobre los diversos intereses que confluyen en estas renuncias, véase a SPIermane, Ole, "Individual Rights, State interests and the Power to Waive ICSID Jurisdiction under 
Así, por ejemplo, resultaría insensato sostener que un individuo, en ejercicio de su autonomía de la voluntad, pueda renunciar a su derecho a la libertad, pues éste es de tal importancia para el derecho y orden público internacionales que su existencia y ejercicio no puede depender de su voluntad. En este sentido se manifestó la Corte Europea de Derechos Humanos ${ }^{26}$ en el caso De Wilde, Ooms y Versyp vs. Bélgica:

"[...] el derecho a la libertad es demasiado importante para una 'sociedad democrática', dentro del significado de la Convención [Europea de Derechos Humanos], como para que una persona pierda el beneficio de la protección de la Convención por la sola razón de que ella renuncie a no ser detenida. Una detención podría violar el artículo 5 , inclusive si la persona en cuestión la ha aceptado. Cuando el asunto es de aquellos que conciernen al orden público dentro del Consejo de Europa, es necesario que los órganos de la Convención realicen una supervisión cuidadosa de todas las medidas que pudieran violar los derechos y libertades que ésta garantiza" 27.

Empero, la Corte Europea de Derechos Humanos, haciendo referencia al caso citado, también sostuvo que si bien "la naturaleza de ciertos derechos protegidos por la Convención es de tal limportancia] que excluye la posibilidad de renunciar a ejercerlos, no se puede decir lo mismo de otros derechos"28. Esto dependería del "texto" y

Bilateral Investment Treaties". En: Arbitration International, Volumen 20. Kluwer Law International, 2004, pp. 179-211.

26. Sobre la jurisprudencia de la Corte Europea de Derechos Humanos, véase a Smermann, Ole, "Individual Rights, State Interests and the Power to Waive ICSID Jurisdiction under Bilateral Investment Treaties". En: Arhitration International, Volumen 20. Kluwer Law International, 2004, p. 186.

27. De Wilde, Oones y Versyp ("Vagrancy") vs. Bélgica, Corte Europea de Derechos Humanos, Decisión sobre el fondo del 18 de junio de 1971, ECHR. Serie A No. 12, par. 65. Traducción del autor de su versión original: "[...] the right to liberty' is too important in a 'democratic socicty " within the mea. ning of the Comention for a person to lose the benefit of the protection of the Convention for the single reason that he gives himself up to be taken into detention. Detention might violate Article 5 (art. 5) even although the person concerned might have agreed to it. When the matter is one which concerns ordre public within the Council of Europe, a scrupulous supervision by the organs of the Convention of all meastures capable of violating the rights and freedoms which it guarantees is neces. sary in every case".

28. Alhert and Le Compte vs. Bélgica, Corte Europea de Derechos Humanos, Decisión sobre el fondo del 10 de febrero de 1983, ECHR Serie A No. 58, par. 35. Traducción del autor. 
del "espíritu" ${ }^{29}$ de las normas que protegen los derechos que se pretenden renunciar. Parecería, además, según la jurisprudencia europea, que es más factible renunciar a derechos procesales ${ }^{30}$ que a sustantivos. En todo evento, la mencionada Corte ha señalado que cualquier renuncia, "siempre que sea permitida, debe realizarse de manera inequivoca" 31 y a condición de que ello "no se oponga a ningún interés público importante"32.

\subsubsection{Propuesta de test}

La jurisprudencia anotada, pese a que pertenece al ámbito de los derechos humanos -cuyos estándares por obvias razones son altos-, bien podría ser utilizada como test para nuestra investigación. Este aventurado ejercicio nos lleva a las siguientes consideraciones:

\section{a) El derecho internacional no prohíbe las renuncias}

No sin antes advertir sobre el carácter limitado de esta investigación, debemos mencionar que no se han encontrado normas positivas del derecho internacional que restrinjan la facultad de un inversionista de renunciar a sus derechos.

En el caso concreto, la renuncia transcrita en la Introducción de este trabajo (contrato con un inversionista español), parecería no violentar el texto o espíritu del instrumento aplicable.

29. Ibidem. Véase tambićn Häkansson y. Sturesson is. Suecia, Decisión sobre el fondo del 21 de febrero de 1990, ECHR Seric A No. 171-A. par. 66.

30. Véanse, por ejemplo, los casos Alhert and Le Compte is. Bélgica, Corte Europea de Derechos Humanos. Decisión sobre el fondo del 10 de febrero de 1983, ECIIR Serie A No. 58, par. 35; Barberá. Messegue y Jahando vs. España, Corte Europea de Derechos Humanos, Decisión sobre el fondo del 6 de dicicmbre de 1988, ECHR Serie A No. 146, par. 82: y Häkansson y' Sturesson is. Suecta, lbidem.

31. Barberú, Messegue y Jahardo vs. España, Ibidem. Traducción del autor đe su original: "Acconding to the Court sestablished case-Ian, waiver of the cxercise of a right guaranted by the Comention - in so fur as it is permissible - must be established in an unequirecal manner"; véase también Albert and Le Compte is. Bélgica, Conte Europea de Derechos Humanos, Decisión sobre el fondo del 10 de febrero de 1983, ECHR Scric A No. 58, par. 35, y Häkunsson y Sturesson us. Suecia. Decisiỏn sobrc el fondo del 21 de febrero de 1990. ECHR Serie A No. 171-A, par. 66.

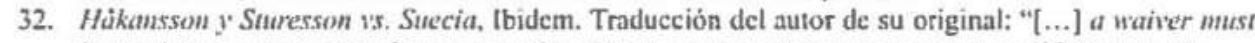
be mude in an unequiveal manner and must not nim coutut to amy important public interest". 
El tratado bilateral de inversiones suscrito entre Ecuador y España no contiene una norma que prohíba la renuncia de los derechos del inversionista a recurrir a los foros de resolución de disputas previstos en el tratado, a saber: a un tribunal ad-hoc conformado de acuerdo al Reglamento de Arbitraje de la CNUDMI o a la jurisdicción del CIADI, a su elección ${ }^{33}$. Asimismo, parecería difícil sostener que algún método de interpretación del derecho pueda llevar a concluir que el espiritu del tratado lo prohíba.

De hecho, el carácter discrecional de la decisión del inversionista reforzaría la idea de que, si éste puede escoger entre las mencionadas dos alternativas, nada le impediría no optar por ninguna de ellas. En otras palabras, el tratado en cuestión no compele al inversionista ni a demandar al Estado ni, si llega a hacerlo, a escoger obligatoriamente entre una de estas alternativas si existe de por medio un acuerdo de las partes de someter sus disputas a otro foro. En este punto, es importante no perder de vista el carácter consensual del arbitraje.

Por lo anterior, se podría corroborar, al menos en este caso, que una renuncia de derechos no infringe el derecho internacional. Hacemos eco de lo decidido en el caso ad-hoc Eureko vs. Polonia:

"El Tribunal nota que la renuncia incondicional contenida en el artículo 1 de la primera adenda, en lo que respecta a los reclamos bajo el TBI, es efectiva y se encuentra en conformidad con el derecho internacional que reconoce que una parte puede renunciar a ciertos derechos protegidos internacionalmente" ${ }^{34}$.

33. Acuerdo para la Promoción y Protección Reciproca de Inversiones entre el Reino de España y la República del Ecuador, 26 de junio de 1996, Articulo XI.

34. Énfasis del autor. Eureko B.Y. is. Polonia, Laudo parcial del 19 de agosto de 2005, par. 174. Tradueción del autor de su versión original: "The Tribmal notes that the anconditional waiver contained in Article 1 of the First Addendum as regards BIT claims is effective and in accondance with international lan' which recognizes that a party may waive certain rights entitled to international prytection". 


\section{b) No es claro si el orden público limita la renuncia de derechos}

Como ha mencionado la Corte Europea de Derechos Humanos, una renuncia de derechos no podría oponerse a "ningún interés público importante" 35 .

Entonces, el análisis que la lógica manda hacer no es simple: determinar si el derecho del inversionista a acudir a los mecanismos de resolución de disputas de un tratado es de tal importancia que su renuncia debería prohibirse por razones de orden público.

La empresa es compleja porque, para empezar, es conocido que no existe una visión uniforme sobre el concepto, alcance y hasta la existencia misma del denominado orden público internacional (o transnacional). Al no existir normas claras sobre la aplicación de este parámetro del test, al menos en el derecho de inversión, el resultado sería siempre subjetivo.

Tal evaluación, que amerita un estudio profundo sobre la naturaleza de los derechos previstos en los tratados bilaterales de inversión vis-à-vis la noción orden público internacional, escapa al alcance de este trabajo. Sin embargo, podemos advertir que la posición de los tribunales, al menos dentro del sistema CIADI, no es unánime.

Por ejemplo, en el caso SGS Société Générale de Surveillance S.A. vs. Filipinas el tribunal, haciendo referencia al caso LaGrand antes mencionado, sostuvo:

"Es dudoso, por decir lo menos, que un particular pueda mediante un contrato renunciar a derechos o dispensar el cumplimiento de obligaciones impuestas sobre los Estados que son parte de tratados bajo el derecho internacional. Pese a que dentro del derecho internacional moderno los tratados pueden conferir derechos sustantivos y procesales a los individuos, normalmente lo hacen con la finalidad de alcanzar algún interés público" 36 .

35. Véase supra nota 32. 
Sin embargo, como se observará en la Sección 3 de este trabajo, otros tribunales CIADI parecen no encontrar impedimentos de este tipo.

\section{c) La renuncia no puede limitar el derecho de una persona a acudir a un tribunal independiente e imparcial}

Parece innecesario extenderse en explicar que el derecho de un inversionista a reclamar sus derechos ante un foro previsto en un tratado no reviste la misma importancia de un derecho como el de la libertad analizado por la Corte Europea de Derechos Humanos. Sin embargo, se debe tomar en cuenta que una renuncia, aunque sea voluntaria -como normalmente es-, no podría resultar en una violación al derecho de las personas a reclamar sus derechos "con justicia" ante "un tribunal independiente e intparcial" ${ }^{37}$.

En el caso que nos ocupa, las estipulaciones contractuales citadas, a más de contener una renuncia de derechos, prevén la selección de un foro arbitral; acuerdos de los cuales, al menos $a$ priori, difícilmente se podría decir que violentan el derecho a recurrir a un tribunal independiente e imparcial. El carácter consensual de la renuncia fortalece esta afirmación, pues se entiende que las partes han seleccionado un foro que consideran apropiado para resolver sus disputas.

36. Énfasis del autor. SGS Socièté Généralc de Survillance $S A$. vs. Filipinas, Caso CIADI No. ARB/02/6, Decisión sobre jurisdicción del 29 de enero de 2004, par. 154. Traducción del autor de su original: "It is, to say the least, doubtfiul that a private party cam by contract waine rights or dispense with the performance of obligations imposed on the States parties to those treaties under international law. Although under medern international law; traties may confer rights, substantice and pircctural, on individuals, they will normally do so in onter to achicve some public interest".

37. Articulo 10 de la Declaración Universal de Derechos Humanos. En el mismo sentido, el Articulo 8(1) de la Convención Americana de Derechos Humanos dispone: "Toda persona tiene derecho a ser oida, con las debidas garantias y dentro de un plazo razonable, por un juez o tribunal competente, independiente $\mathrm{e}$ imparcial, establecido con anterioridad por la ley, $[\ldots]$ para la detertrinación de sus derechos y obligaciones de orden civil, laboral, fiscal o de cualquicr otro carácter". 


\section{d) Las renuncias deben ser inequivocas}

La jurisprudencia de la Corte Europea de Derechos Humanos, que considera que una renuncia de derechos debe ser inequívoca, es consistente con lo decidido por tribunales CIADI. Por ejemplo, en el caso Waste Manngement vs. México, el tribunal, a más de hacer una interesante acotación sobre el efecto jurídico de una renuncia, puntualiza las formalidades para su validez:

"El acto de renuncia, de por sí, es un acto unilateral, ya que su efecto extintivo se ocasiona únicamente por su voluntad. La exigencia de una renuncia en cualquier contexto implica una dejación voluntaria de derechos en cuanto que, en términos generales, este acto produce una sustancial modificación en la situación jurídica preexistente: la pérdida o extinción del derecho. Por lo tanto, renunciar supone el ejercicio de la facultad de disposición de su titular para dar lugar a ese efecto jurídico.

En todo caso, cualquier renuncia debe ser clara, explicita y terminante, sin que sea lícita deducirla de expresiones de dudoso significado" 38 .

Las estipulaciones contractuales en estudio parecerían ser lo suficientemente claras, explícitas y terminantes, al contener la voluntad inequívoca de las partes de renunciar a los mecanismos de solución de controversias constantes en los respectivos TBIs.

\section{La ReNUNCIA EN LA PRÁCTICA. UNA POSICIÓN EN EVOLUCIÓN}

Varios tribunales arbitrales han tratado indirectamente la materia de esta investigación, sin que hayan adoptado posicio-

38. Énfasis del autor. Naste Afanagement, Inc. ws Estudos Unidos Mexicanos, Caso ClADI No. ARB/98/2, Laudo del 2 de junio de 2000, par. 18. 
nes integrales. De hecho, hay tribunales que han adelantado su opinión advirtiendo que no estaban obligados a hacerlo. ${ }^{30}$ Esta actitud podría tener, en parte, una explicación, pues los tribunales aún no se han enfrentado a casos de renuncias expresas como las analizadas en este trabajo; más bien, en la mayoría de ocasiones, han examinado renuncias inferidas por la existencia de cláusulas de selección de foro.

A pesar de esta incertidumbre, existen en las decisiones arbitrales al menos dos criterios que quisiéramos resaltar: la diferenciación entre jurisdicción exclusiva o alternativa y la preeminencia de la autonomía de la voluntad.

\subsection{Jurisdicción Alternativa o Exclusiva}

Cuando un contrato contiene una cláusula por la que las disputas se someten a un foro distinto al previsto en un tratado, es necesario preguntase si ello representa la selección de una jurisdicción exclusiva, como única opción para resolver las disputas entre el inversionista y el Estado anfitrión, o si, por el contrario, representa una opción adicional a los medios pactados en el tratado, de entre los cuales se puede escoger libremente.

En el caso Lanco International Inc. vs. Argentina, el tribunal arbitral sostuvo que una cláusula que remitía las disputas de un contrato a la jurisdicción de los Tribunales Contencioso Administrativos Federales de Argentina, no podía considerarse como un reemplazo al consentimiento que el Estado anfitrión había otorgado a la jurisdicción del CIADI en el tratado. "Tal estipulación, por el contrario, sólo diluye la presunción de exclusividad del arbitraje CIADI" 40 , lo cual, al parecer del tribunal, se encontra-

39. Ver infra nota 51.

40. Lanco International lnc vs. Argentina, Caso CIADI No, ARB/97/6, Decisión preliminar sobre jurisdicción del 8 de diciembre de 1998, 40 ILM 457, 2001, (en adelante "Lanco"), par. 38. Traducción del autor de su original: "[...] the allegation by the Argentine Republic cannot he sustained, conside. ring that the stipulation to the contran: if it exists, does not replace any consent, but instead dilutes the presumption as to the exclusitity of ICSID arbitration[... [". 
ría en conformidad con el artículo 26 del Convenio de Washington ${ }^{41}$ que deja abierta la posibilidad de que la jurisdicción del CIADI no sea exclusiva.

Por otra parte, los tribunales también han evaluado si el foro seleccionado en un contrato estaría de todas maneras disponible en ausencia del convenio arbitral, como normalmente ocurre con la jurisdicción de las cortes locales, o si, por el contrario, la opción nace de la voluntad de las partes.

Los tribunales de Lanco y Salini vs. Marruecos consideraron que una cláusula que remite una disputa a las cortes del Estado anfitrión, mismas que de no existir el convenio arbitral igual tendrían, por ley (mas no por contrato), jurisdicción sobre la diferencia, no puede considerarse como una verdadera selección de jurisdicción bajo el principio de la autonomía de la voluntad ${ }^{42}$. Éste no sería el caso, a criterio del tribunal de Lanco, si el foro seleccionado fuese arbitral ${ }^{43}$.

Sin embargo, esta posición fue posteriormente rebatida por el tribunal del caso SGS vs. Filipinas, que consideró que un acuerdo debe siempre ser respetado, salvo que exista otra norma contraria que prevalezca, sin importar si se otorga jurisdicción a cortes ordinarias o a un tribunal arbitral. ${ }^{4+}$

41. Articulo 26 del Convenio de Washingion: "Salvo estipulación en conurario, el consentimiento de las partes al procedimiento de arbitraje conforme a este Convenio se considerará como consentimiento a dicho arbitraje con exclusión de cualquier otro recurso". Énfasis del autor.

42. Lanco, par. 26: "This Tribunal unterstands that the [contractual] stiputation.... according to which the parties shall submit to the jurisdiction of the Federal Contentious-didministrative Tribunals of the City of Buenos dires, cannot be considered a previously agreed dispute-settlement procedure. The Parties could have foreseen submission to domestic or internutional arbitration, but the choice of a national forum could only lead to the jurisdiction of the...tribunals, since administrative jurisdiction cannot be selected by mutual agreenent [...] [T] he contentious-administrative jurisdiction cannot be selected or waived [...]". El tribunal de Salini Construttori S.P.A e halstrade S.A. vs. Marruecos, por su parte, sostuvo que: "As the jurisdiction of the administrative courts cannot he opted for, the consent to ICSID arbirration jurisdiction ....shall prevail over the consent of Article 52 of the CCAG. since this srticle cannot be taken to be a clause truly extending the scope of jurisdiction and corvered by the principle of the Parties "autonomy". Caso CIADI No. ARB/00/4, Decision sobre jurisdicción del 23 de julio de 2001, 42 IL.M 609, 2003, par. 27.

43. Thid.

44. Socièté Ginèrale de Sunvillance S.d. is. Filipinas, Caso CIADI No. ARB/02/6, Decisión sobre jurisdicción del 29 de enero de 2004, par. 138: "In accontance with general principle, courts or tribusals 
Con la llegada de este caso la discusión tomó otro rumbo. El tribunal se planteó la interrogante desde otra perspectiva: ¿Puede un inversionista acudir a una instancia arbitral pactada en un tratado no obstante la existencia de una cláusula contractual que prevé un foro distinto -al menos para reclamos contractuales?

La respuesta del tribunal fue negativa porque (i) en virtud del principio maxim generalia specialibus non derogant, una cláusula específica de un contrato debe prevalecer sobre una general de un tratado; es decir, "no se presume que tal estipulación general tenga por efecto invalidar las estipulaciones especificas de contratos particulares que han sido negocindos libremente por las partes" 45 ; y (ii) "los acuerdos de protección de inversiones, como tratados marco, no tienen la intención de superponerse o reemplazar a los acuerdos existentes y negociados entre un Estado y un inversionista, sino de complementarlos y darles soporte" 4 .

La visión del tribunal de SGS vs. Filipinns fue, a su vez, de cierta manera refutada por otros tribunales como el del caso Siemens vs. Argentina que consideró que tanto las alternativas de resolución de conflictos de un tratado como las de un contrato podrían subsistir, sin ser exclusivas ${ }^{47}$. Este pensamiento coincide

should respect such a stipulation in proceddings between those parties, unless they are bound ab exterior, i,e. by some other law, not to do so. Moreover it should not matter whether the contractuallyagreed forum is a municipal court [...] or domestic arbitration... or some other form of arbitration. e.g. pursuant to the UNCITRAL or ICC Rules".

45. Sociétí Générale de Suncillance S.A. vs. Filipinas, Ibid, par. 141. Traducción del autor de su versión original: "It is not presumed that such a general provision has the effect of overriding specific provisions of particular contracts. frecty negotiated between the parties. Este criterio no está excnto de criticas, pucs, para otros, el acuerdo arbitral basado en un tratado es más especifico que uno contractual: "The Tribunal's reasoning ignores the fact that the dispute settlement clause in the BIT is mercly' a standing offer to investors. By accepting that offer an investor perfects a specific arbitration agreement... follows that the ICSID arbitration agrement is the more specific one". SCHREUER, Christoph. "Calvo's Grandehildren: The Return of Local Remedies in Investment Arbitration". En: The Law and the Practice of International Courts and Tribunals. Leiden: Koninklijke Brill NV, 2005, p. 10.

46. Ibid. Traducción del autor de su versión original: "[...] an investment protection agrement as a framework treaty: [is] intended by the State parties to support and supplement, not to override or replace, the actually negotiated investment arrangements made between the investor and the host State". Véase también el par. 153: "The Tribunal cannot accept that standart BIT jurisdiction clauses automatically override the biding selection of a forum by the parties to determine their contract claims". 
con el del árbitro (parcialmente) disidente en el caso SGS vs. Filipinas, quien además señaló que, en estos casos, el actor tiene el derecho de seleccionar entre los foros alternativos ${ }^{48}$. Se debe advertir, empero, que estos razonamientos están ligados a los que han sustentado la conocida dicotomía entre reclamos contractuales y reclamos basados en un tratado ${ }^{49}$; tema que no será abordado en este ensayo.

\subsection{Preeminencia de la Autonomía de la Voluntad}

El principio de la autonomía de la voluntad ha tenido importancia para los tribunales al momento de analizar (al menos indirectamente) la renuncia de derechos.

La primera decisión que amerita ser mencionada es la del tribunal de anulación del caso Vivendi, que, al tiempo de sostener que una cláusula de selección de foro local "no afectaba la jurisdicción del tribunal con respecto a una reclamación basada

47. Siemens d.G. vs. Argentina, Caso CIADI No. ARB/02/8, Decision sobre juristlicción del 3 de agosto de 2004, par. 181. Este punto de vista es compartido por Scilneuer quien propone que "[a] better approach might be to abandon the idea of mutually exclitsive competences. The jurisdictions of inter. national tribunals and of domestic courts do not necessarily. 'override' or 'replace' one another". SCHREuer, Christoph. "Calvo's Grandehildren: The Return of Local Remedies in Investment Arbitration". En: The Law and the Practice of International Courts and Trihunals. Leiden: Koninklijke Brill NV, 2005, p, 11.

48. "It is my understanding that the most significant advantage which, in practice, is granted by a BIT to foreign investors is, precisely: the right to sclect, amongst the alternative fourums made available by the BIT, the forrum that the investor dcems the most suitable to him after that the elentents of fact or law of the dispute have beconc clear". Société Gémérale de Surreillance S.A. is. Filipinas, Caso CiADl No. ARB/02/6, Declaración suplementaria del árbitro Antonio Crivellaro, 29 de enero de 2004, par. 5.

49. Por cjemplo, el tribunal del caso Jivendi sostuvo que una cláusula que contenia la selección de las cortes de Tucumán como foro exclusivo para resolver disputas no constituia una renuncia del inversor a la opción de arbitraje intemacional bajo un tratado porque, inter alia, los reclamos presentados por las demandanies no se encontraban fundamentados en un contrato sino en un tratado. Compañia de Aguas del Aconquija S.A. y Compagnic Génírale des Eanzx vs. Argentina, Caso Ciado No. ARB/97/3, Laudo de 21 de noviembre de 2000, par. 53. Sin embargo, cl Comitć Ad-hoc de anulación de este caso sostuvo que los reclamos contractuales estarian prima facic dentro del aicance del TBI y, por tanto, un tribunal arbitral tendria competencia para decidir también sobre estos reclamos. El Comitć tambiẻn mencionó que "el hecho de que el Contrato... remitia las diferencias contractuales a los tribunales en lo contencioso-administrativo de Tucumán no afectaba la jurisdicción del Tribunal con respecto a una reclamación basada en las disposiciones del TBI". Compañia de Aguas del Aconquija S.t. y Fivendi Unirersal (anter Compagnic Ginerale dex Eanx) is. Argentina, Decisión de anulación, $3 \mathrm{de}$ julio de 2002, par. 55 y 98 . 
en las disposiciones del TBI", afirmó que "[l]a Cláusula...del Contrato...no pretendia expresamente excluir la jurisdicción de un tribunal internacional que deriva del...TBI, y cuando muy menos, una indicación clara de excluir dicha jurisdicción seria necesaria" ${ }^{\prime 31}$.

En consecuencia, parecería que si las partes hubieren pactado claramente que la selección de un foro local excluía la jurisdicción del CIADI, el tribunal habría considerado tal voluntad como una renuncia válida.

Posteriormente, en una decisión que hasta el momento es la más concluyente sobre el tema, el tribunal del caso Aguas del Tunari vs. Bolivia, haciendo referencia a la opinión de Ole SPIERMANN, sostuvo que:

"[...] si las Partes hubieran acordado claramente la renuncia a la jurisdicción del CIADI, esa renuncia sería eficaz. Dado que parece claro que las partes de un arbitraje CIADI podrían convenir mutuamente en un mecanismo diferente al CIADI para la resolución de sus controversias, parecería que un inversionista puede también rentunciar a su derecho de invocar la jurisdicción del CIADI"51.

Pese al lenguaje condicional utilizado, la posición del tribunal es evidente. Lamentablemente, a nuestro criterio, su eficacia como precedente se ve mermada por el hecho de que el tribunal, dadas las características de la disputa, no necesitaba llegar a tal conclusión. Tanto es así, que el párrafo citado concluye advirtiendo: "[n]o obstante, el Tribunal no tiene por qué pronunciarse sobre este tema en el caso de autos".

Por último, el tribunal del caso Occidental vs. Ecundor, siguiendo la línea del caso Aguns del Tunari S.A. vs. Bolivin, advir-

50. Énfasis añadido. Jhid.. par. 76. La versión en inglés de la decisión aclara el lenguaje de esta última frase: " $[. .$.$] at the very least, a clear indication of an intention to exchule that jurisalictions would bo$ required".

51. Énfasis del autor. Aguas del Timari S.A. us. Bolivia, Caso CIADI No. ARB/02/3, Decisión sobre jurisdicción del 21 de octubre de 2005, par. 118. 
tió que "'[e]l Tribunal no interpretará una cláusula ambigua como una renuncia implícita a la jurisdicción del CIADI; el silencio, en tal sentido, no es suficiente.' Esta advertencia es pertinente en el presente caso, y este Tribunal la adopta»,52 agregando que:

"Si las partes hubieran tenido la intención de excluir las diferencias de caducidad del arbitraje del CIADI y conferir competencia exclusiva a los tribunales de lo contencioso administrativo ecuatorianos muy fácilmente podrían haberlo hecho, utilizando un texto similar al que aparece en las disposiciones arriba citadas $[\ldots]^{\prime \prime 53}$.

Entonces, aparentemente este tribunal también hubiera aceptado como válida una renuncia a la jurisdicción del CIADI si su lenguaje hubiese sido inequívoco ${ }^{54}$.

\section{Conclusiones}

Se deja expuesta en esta investigación la complejidad del denominado derecho de inversión, donde confluyen y deben acoplarse el derecho internacional público y el privado.

Las nuevas situaciones del comercio internacional y las recurrentes relaciones entre entes privados e instituciones estatales, hacen manifiesta la necesidad de que el derecho internacional se adapte a ellas, conjugando equilibradamente los intereses internacionales, estatales y privados en juego. Para ello, parecería prudente alejarse de la rígida dicotomía entre el derecho internacional público y el privado y admitir la existencia, al menos en ciertas áreas, de sistemas híbridos, en evolución.

52. Occidental Petroleam Corporation, Occidental Exploration and Production Compuny is, Ecnador, Caso ClADI No. ARB/06/11, Decisión sobre competencia del 9 de septiembre de 2008, par. 72.

53. Ibid, par, 81 .

54. Cabe mencionar que este tribunal, para alcanzar tales conclusiones, se alcjó de la línca de otros tribunales que analizaron in extenso la naturaleza de los reclamos y el efecto de una cláusula de selección de foro local sobre la jurisdicción de un tribunal CIADI, pues su análisis se circunscribió más bien a interpretar el texto del contrato donde no encontró una renuncia expresa a la jurisdicción del CIADI. 
Pese a la novedad del tema, es decidora la posición de la jurisprudencia y doctrina sobre la capacidad directa que tienen los particulares de ejercer derechos y cumplir obligaciones emanados del derecho internacional. Parecería, de hecho, que lo que expuso KELSEN hacia varias décadas recobra vigencia:

"Es al hombre a quien se dirige las normas del Derecho internacional; es contra el hombre que se dirige la coacción; es a los hombres a los que encomienda el cuidado de crear el orden [...] Existen normas del Derecho internacional que determinan o rigen directamente al individuo" 55 .

Y, precisamente, una manera de hacer uso de esa facultad de disposición, como lo aclaró el tribunal de Waste Mantagement vs. México, es extinguir un derecho de manera voluntaria y unilateral, mediante una renuncia, sujeto siempre a los límites del derecho y orden público internacionales.

La renuncia de derechos y la simultánea selección de un foro arbitral pactadas en las disposiciones transcritas en la Introducción, parecerían pasar el test basado en la jurisprudencia existente, salvo el filtro del orden público internacional sobre el cual aún son necesarias más claridad y reflexión.

En el ámbito del arbitraje CIADI, existen decisiones que, a pesar no haber abordado (o debido abordar) directamente las renuncias en estudio, se inclinan a considerarlas válidas, haciendo uso de la teoría de los derechos directos. Debemos señalar, sin embargo, que éstas aún no conforman un cuerpo sólido y uniforme sobre la materia, por lo que bien podrían ser rebatidas en futuros casos.

55. Cabe mencionar que este tribunal, para alcanzar tales conclusiones, se alejó de la linea de otros tribunales que analizaron in extenso la naturaleza de los reclamos y el efecto de una clíusula de selección de foro local sobre la jurisdicción de un tribunal CIADI, pues su análisis se circunscribió más bien a interpretar el texto del contrato donde no encontró una renuncia expresia a ta jurisdicción del CIADI.

56. KleLSEN, Hans. Curso dictado en la Academia de Derecho Internacional de la Haya. En: Recucil des Cours, La Haya: Martinus Nijhof Publishers, 1932, p. 143. 
En lo personal, creemos que los tribunales deben poner especial atención a la voluntad de las partes en virtud del carácter consensual del arbitraje. De no encontrar normas positivas o razones de orden público internacional suficientes para limitar la facultad de los particulares de disponer de sus derechos, las renuncias libremente pactadas y encaminadas a extinguir tales derechos deberían ser respetadas. 